\title{
Simulations for determining the optimal enhancement ratio threshold for segmentation of left atrial fibrosis
}

\author{
Dana C Peters ${ }^{1 *}$, Litten K Bertelsen ${ }^{2}$ \\ From 18th Annual SCMR Scientific Sessions \\ Nice, France. 4-7 February 2015
}

\section{Background}

Segmentation of enhanced signal on late gadolinium enhancement (LGE) images of the eft atrium (LA) is required for characterizing left atrial fibrosis. However, the analysis is challenging, because the atrial fibrosis is not readily visually apparent. Recently, a study advocated using enhancement ratio (ER, atrial wall to blood) to segment the atrium, and found that an ER of 1.6 corresponded to very low voltage on EP mapping $(<0.1 \mathrm{mV})$ (1). Use of ER for thresholding is attractive, because thresholds based on CNR values (typically 3.5) or visually chosen are sensitive to underlying SNR. We sought to investigate the capabilities of ER for segmentation, using simulations.

\section{Methods}

Simulations using Bloch equations modeled the signal intensity of an $1 R R$ inversion recovery spoiled gradient echo sequence, with inputs of TR, $\theta$, constant RR interval, views per segment (vps), TI, and $\mathrm{T} 1$, assuming centric order. All simulations used typical values of $\mathrm{TR}=4.4 \mathrm{~ms}, 33$ vps, $\theta=15 \mathrm{deg}, 1000 \mathrm{~ms} R \mathrm{R}$, and TI set to null normal myocardium. Experiments were performed on a 1.5T Siemens using T1 standards, and typical protocol parameters to confirm simulations with respect to ER. Next, for a range of expected blood $\mathrm{T} 1\left(\mathrm{~T}_{\mathrm{b}}\right)$ values (300 to $370 \mathrm{~ms}$, at 20 to 50 minutes post injection) (2), the atrial myocardium $\mathrm{T} 1$ $\left(\mathrm{T} 1_{\mathrm{a}}\right)$ values were calculated. $\mathrm{T} 1_{\mathrm{a}}$ was calculated for each extra-cellular volume fraction (ECV) value of interest (2), using $\mathrm{T}_{\mathrm{b}} 0$ of $1500 \mathrm{~ms}$ and $\mathrm{T} 1_{\mathrm{a}} 0$ of $900 \mathrm{~ms}$, with $\mathrm{R} 1=4.5 \mathrm{~L} /$ $\mathrm{mMol} / \mathrm{s}$ and hematocrit $\mathrm{HCT}=0.46$. The $\mathrm{T}_{\mathrm{a}}$ and $\mathrm{T} 1_{\mathrm{b}}$ were

'Diagnostic Radiology, Yale School of Medicine, New Haven, CT, USA Full list of author information is available at the end of the article

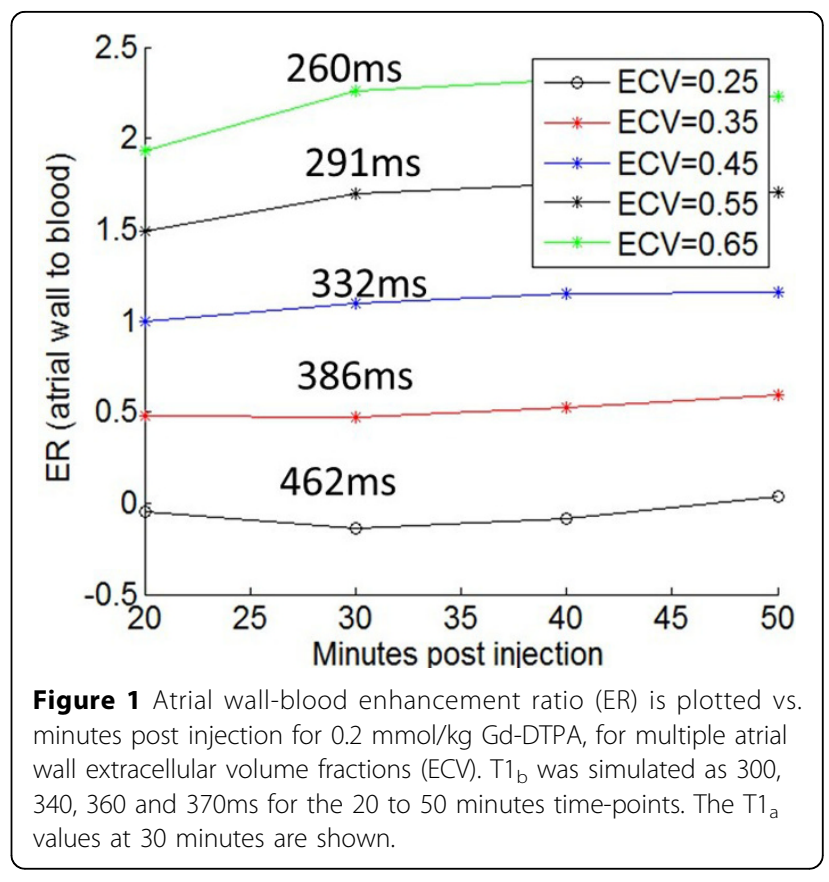

input into the validated Bloch simulations to calculate the ER.

\section{Results}

Comparing experimental and simulated ERs for a range of T1s and imaging protocols, we found good agreement. Figure 1 plots ER, for ECV values from 0.25 (normal myocardium) to 0.7 (abject scar). Simulations show ER is not strongly dependent on heart-rate but is dependent on nulling. Note that imaging later post injection is helpful. Also note that partially fibrotic tissue (i.e. ECV $>0.5$ ) can be visualized, with an ER $>1.3$. Figure 2 shows the results of segmenting an LGE slice, which has ablation 


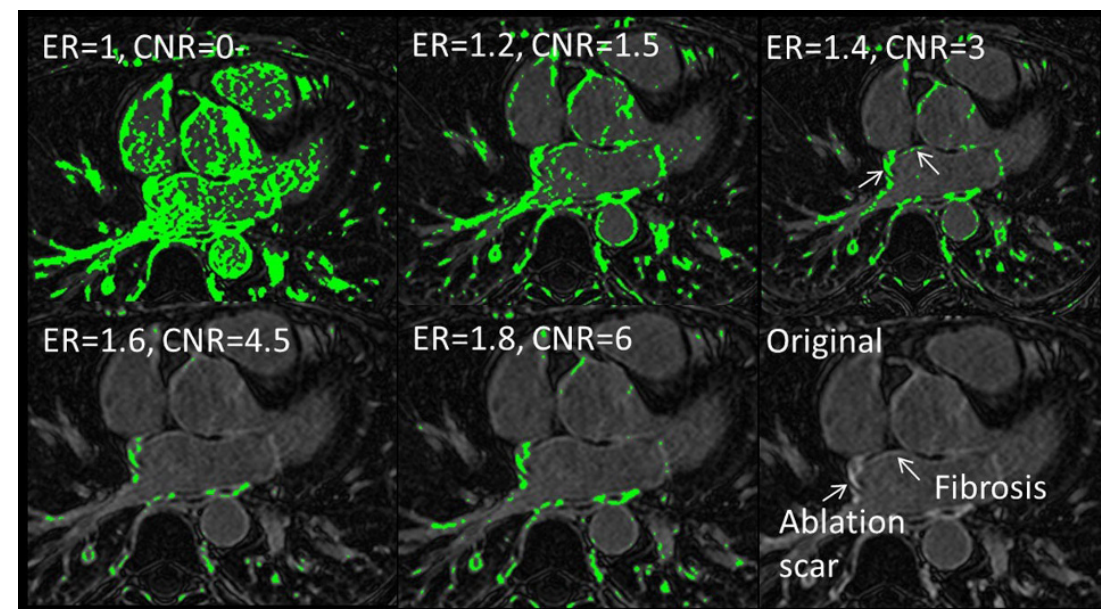

Figure 2 Example of using ER to segment LGE images.

scar and atrial fibrosis. In these segmentations, CNR and ER are given. Figure 2 demonstrates that an ER threshold of 1.4 includes both atrial fibrosis and scar.

\section{Conclusions}

These simulations find that an ER > 1.6 indicates an ECV $>0.55$, which corresponds to very fibrotic myocardium, in agreement with Khurram et al. Furthermore, an ER of 1.4 is a practical threshold which permits segmentation of partially fibrotic tissue.

\section{Funding}

We gratefully acknowledge support from NHLBI R01HL113352.

\section{Authors' details}

'Diagnostic Radiology, Yale School of Medicine, New Haven, CT, USA

${ }^{2}$ Cardiology, Copenhagen University Hospital, Copenhagen, Denmark.

Published: 3 February 2015

\section{References}

1. Khurram IM: Heart Rhythm 2014, 11:85-92.

2. Klein C: JMRI 2004, 20:588.

doi:10.1186/1532-429X-17-S1-P60

Cite this article as: Peters and Bertelsen: Simulations for determining the optimal enhancement ratio threshold for segmentation of left atrial fibrosis. Journal of Cardiovascular Magnetic Resonance 2015 17(Suppl 1): P60.

\section{Submit your next manuscript to BioMed Central} and take full advantage of:

- Convenient online submission

- Thorough peer review

- No space constraints or color figure charges

- Immediate publication on acceptance

- Inclusion in PubMed, CAS, Scopus and Google Scholar

- Research which is freely available for redistribution
Bïmed Central 